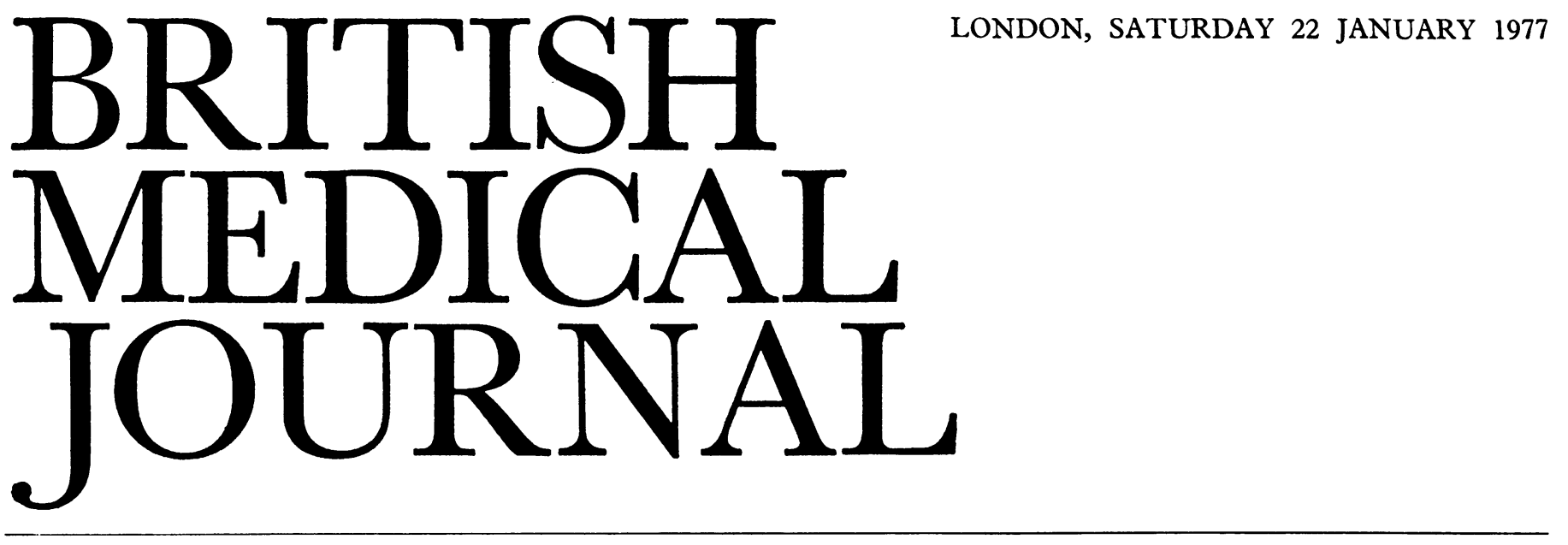

\title{
Adjuvant therapy of lung cancer: Now sits expectation in the air
}

The results of lung resection for cancer seem to be remarkably constant, with a five-year survival between 25 and $30 \%$ independent of the surgical technique or the histological cell type. ${ }^{12}$ Immense efforts have gone into trying to improve these depressing figures, yet the disease remains stubbornly resistant to the doctors' stratagems-grave news for the greater part of the victims of this disease who fail even to qualify for resection.

Scott $e t a l^{2}$ have just published the outcome of the Medical Research Council's long-term double-blind trial of chemotherapy as an adjuvant to surgery for lung cancer. Of 243 patients initially allocated busulphan, 234 cyclophosphamide, and 249 placebo, survival rates at five years were $28 \%, 27 \%$, and $34^{\circ}{ }^{\circ}$, respectively. Analysis failed to show any subset of patients who had been helped by either drug regimen. Perhaps the plan of treatment was not particularly aggressive, even though the dosage of busulphan carried a high risk of thrombocytopenia. Experience with intermittent cyclophosphamide ${ }^{3}$ has shown that treated patients may have a higher mortality rate than controls. At least the cyclophosphamide schedule chosen for the MRC trial did not hasten the patients' demise -but equally it was ineffective.

The result of the MRC trial is typical of many trials started around the beginning of the '70s and now drawing to a close. Based on studies of advanced disease some oncologists are now advocating high dose intermittent polychemotherapy as the next type of adjuvant programme to be evaluated. ${ }^{2}$ Such tactics will place heavy demands on medical resources, and the patients will be tied to their clinics because of the needs for close haematological control of highly toxic agents and to give the drugs intravenously. Despite all these drawbacks there are clinics in the Western world where such plans are usedreflecting doctor-patient relationships that are often different from that underlying British practice.

The recent meeting of the Medical Oncology Society in Nice highlighted some of the differences in attitudes within Europe towards the problem of the adjuvant treatment of lung cancer. Taking operability as the point of departure, but excluding small cell tumours, which most surgeons shun, some schools of thought favoured pre- or post-operative radiotherapy, while others seemed content to settle for chemotherapy or immunotherapy. To circumvent the demands of intravenous therapy complex combinations of several oral chemotherapy agents have been suggested: melphalan, cyclophosphamide, 5-fluorouracil, and others being blended on the basis of empiricism, caution, and experience. The most rational therapists seem to believe it is their duty to soldier on with chemotherapy for lung cancer, but they admit that the chance of hitting on a successful combination is small. As the number of drugs increases (and their scheduling and dosage add further factors into the mix), the way even a few can be arranged soon reaches large numbers. Those heavily engaged in the exploration of the powers of polychemotherapy in lung cancer seem to believe, like the generals of Verdun or on the Marne, in carrying the day by the sheer weight of the onslaught. So far, the war is locked in stalemate, and the daily casualty list is appalling.

Yet if all seems gloomy on the chemotherapy front-when viewed from the point of real advance and not transient palliation-are there glimmers of hope from other quarters? The enthusiasts for immunotherapy are well represented at every clinical cancer meeting, and Nice was no exception. Professor R Baldwin, reviewing the changing world of tumour immunology, thought that the original concept that human tumours are antigenic and that immunotherapy may aid their elimination by an immune reaction was no longer tenable. It now seems that non-specific stimulation by BCG and other bacterial products results in activation of macrophages, so aiding their aggressiveness towards tumour cells. The promising results of contact adjuvant immunotherapy in lung cancer, using the intrapleural instillation of BCG after resection, seem still to be holding up 10 months after McKneally's original report. ${ }^{4}$ A comparable study in Japan appears to be getting responses that warrant cautious optimism. The sceptics say that putting BCG in the pleural cavity is a good way of producing adhesions but still need convincing that it does anything else. Surgeons contemplating this treatment should be aware that McKneally gives the patients isoniazid for 12 weeks to prevent undue growth of the BCG organisms.

The enthusiasts for levamisole are now promoting a new image for this drug: apart from its undisputed anthelmintic action it is to be known henceforth as an "immune-restorant," whatever that may be, having failed to make the grade as an immune stimulant. The initial disappointing results from the use of levamisole in cancer may now, it seems, be explained 
as the consequence of getting the dose wrong (it was beneficial only if the patient weighed less than $70 \mathrm{~kg}$ ). This time the recommended dose is $100 \mathrm{mg} / \mathrm{m}^{2}$ on two consecutive days per week-but this regimen is not entirely innocuous, for leucopenia may occur, though it is reversible on stopping the drug.

This pastiche gives only a glimpse of a very complicated problem that has baffled the experts so far. Priestley.5 advised us to find the right balance of credulity and scepticism, despite the apparent paradox, if we were to find our way through a dark and difficult situation. Honest doctors, beset by the growing band of fanatical believers who hover around the meeting places of the jet-set oncologists, must be on their guard. So far the story is like The Tales of Hoffmann, with the thoracic surgeon in the role of the poet. The first act has been his encounter with chemotherapy and radiotherapy, and we are now watching and waiting to see if immunotherapy will steal his shadow and glide away with its next victim. Perhaps there is still time to write the demonic Dr Miracle out of the last act.

1 Selawry, O S, and Hansen, $\mathrm{H} \mathrm{H}$, in Cancer Medicine, eds J F Holland and E Frei III, p 1473. Philadelphia, Lea and Febiger, 1973.

2 Stott, H, et al, British fournal of Cancer, 1976, 34, 167.

${ }^{3}$ Brunner, K, Marthaler, T, and Muller, W, Cancer Chemotherapy Reports, 1973, 4, suppl 153

${ }_{4}^{4}$ McKneally, M F, Maver, C, and Kausel, H W, Lancet, 1976, 1, 377.

5 Priestley, J B, Over the Long High Wall. London, Heinemann, 1972.

\section{Kidneys from cadavers}

The supply of donor kidneys for patients with chronic renal failure has not improved: some 600 kidneys are transplanted each year in Britain, whereas over 2000 patients need treatment. Health Service costs are now coming under closer scrutiny, and the expenditure on the care of those suffering from renal failure was recently discussed in the House of Commons. The Minister of State, Mr Moyle, estimated that the cost of dialysing 2500 patients with chronic renal failure was about $£ 17$ million per year, excluding any capital element ${ }^{1}$; so that if all the patients who develop renal failure were treated by dialysis the NHS would have to find an additional $£ 17$ million every year. A successful kidney transplant represents a substantial saving of money, quite apart from the physical and psychological advantages over dialysis for the patient.

Although the results of kidney transplantation have changed little in the past decade, a worthwhile result is achieved in about half the patients given cadaver kidneys. Long-term survivors have reached their tenth and eleventh year after transplantation with continuing good function in their allografts. For a kidney to be rejected is a tragedy which at present cannot be avoided, but graft failure for technical reasons is in another category of disaster. Unfortunately, the shortfall of kidney donors is so serious that many transplant surgeons are prepared to use organs that are less than satisfactory. For example, organs are being taken from patients who have been on ventilators for so long that they have developed lung infection and septicaemia; kidneys are removed from patients brought in dead from accidents when the time taken to find the relatives and seek permission has resulted in excessive damage from ischaemia. Removal of the kidneys after death is a difficult operation, often undertaken by relatively junior surgeons in an atmosphere of haste.
In the United States primary technical failures are very rare, since the public has accepted the concept of brain death, and most kidneys are now removed from patients with irreversible complete brain damage but an intact circulation. Moreover, surgeons removing kidneys receive a handsome fee (though they may be in danger of malpractice litigation should they make a technical error and damage the transplant). Organ perfusion apparatus is frequently used in the United States, preserving the kidney for up to two days ${ }^{2}$; the recipient operation may then be fitted into an operating list for the convenience of the hospital, and there is time to prepare the recipient and perform complicated matching procedures.

An analysis of 431 cadaver kidneys available for transplantation recently reported from Boston Veterans' Administration Hospital $^{3}$ showed that 75 were discarded after a period of pulsatile perfusion on a preservation machine. These kidneys were considered unsuitable for transplantation because of poor flow characteristics on the machine, multiple arteries with segmental obstruction, prolonged warm ischaemia time, or malfunction of the pump. Differences in the type of pretreatment given to the donors before removal of kidneys had important consequences. Thus $70^{\circ} \%$ of the kidneys that were transplanted came from donors that had been given phenoxybenzamine, methyl prednisone, or phentolamine, whereas only $33 \%$ of kidneys discarded were taken from donors who had received such pretreatment.

Provided that the death of the donor has been established by using criteria such as those recently agreed by the Conference of Royal Colleges and Faculties, ${ }^{4}$ is there any reason why drugs that improve the quality of the organs for transplantation should not be given to the patient before they are removed ? Nevertheless, such treatment does add an extra complication. Whereas in Holland, for example, the need to pay for the extra work of removal of kidneys for transplantation has been accepted (and there have been no reports of abuse), in Britain removal of cadaver organs leads to extra unpaid work, often both difficult and harrowing, for the doctors and nurses concerned in the care of ventilated patients with brain death. This may be one of the reasons for the apathy described in a recent report published by the Transplantation Society. ${ }^{5}$ These matters should be widely discussed, and it is up to the profession and public opinion to decide whether or not patients awaiting kidney transplantation should be denied this treatment.

In practice, public attitudes to transplantation appear to be favourable. The survey by Moores et $a l^{6}$ showed no evidence of any widespread objection to the procedures required for obtaining cadaver kidneys, yet only $4.4 \%$ of the people interviewed had completed a donor card. The willingness of the community to co-operate had not been developed to anything remotely approaching its full potential. In Australia and Canada driving licences contain a section for consent to be given to organ donation, yet when this matter was raised in the House of Commons Mr Moyle stated that, though sympathetic to the aims of the proposals, he thought that practical difficulties would prevent use of driving licences for this purpose. ${ }^{7}$ Why should this be possible in other countries but not in the United Kingdom?

\footnotetext{
${ }^{1}$ British Medical fournal, 1976, 2, 1269.

2 Sullivan, M J, et al, Archives of Surgery, 1976, 111, 1103.

${ }^{3}$ Filoso, A M, and Cho, S I, Archives of Surgery, 1976, 111, 1129.

Conference of Medical Royal Colleges, British Medical fournal, 1976, 2, 1187.

${ }^{5}$ British Transplantation Society, British Medical fournal, 1975, 1, 251.

Moores, B, et al, British Medical fournal, 1976, 1, 629.

7 British Medical fournal, 1976, 2, 1207.
} 